\title{
Scholarly Dispositions in an Online Doctoral Program
}

\author{
Heather Greenhalgh-Spencer \\ Texas Tech University
}

Within the last decade, my institution, which resides within the United States, has achieved R1 (Very High Research Activity) status. ${ }^{1}$ We have significantly increased the number of doctoral students that we admit and that we graduate, and — as a way to "respond to the market"-we have moved a number of courses and even whole doctoral degree programs online. As of this writing, a majority of our doctoral students are now online students. This has become increasingly true as our university has grappled with the fall-out of COVID-19, including the Delta variant. Multiple questions have become salient for us: What do students miss out on as online students, and do the things they miss out on make a difference for future success as a scholar? Are there things we need to do differently for our online doctoral students? Th e s e questions have led me to think more deeply about scholarly dispositions. My "theory of action" is that if we can name dispositions that lead to becoming a "successful scholar" then we can backward-design doctoral programs to create opportunities for students to gain these dispositions. To that end, I am interested in wrestling with the following questions: What is a disposition? Why is it important to think about experiences of online graduate students from the standpoint of "disposition"? And how might we facilitate scholarly dispositions in online doctorate programs (admitting, up front, that there are some difficulties inherent in online programs)? The main goals of this article are to elucidate the challenges and practices that a dispositional standpoint allows us to think about and understand vis a vis the experience of online doctoral students, as well as to ground future research on practices for dispositional accrual for 
online doctoral students. I begin with defining "dispositions."

\section{WHAT IS A DISPOSITION?}

There are many different definitions of "disposition." One of the definitional debates stems from the psychological definition of dispositions as opposed to the virtue ethics definition of dispositions. Psychologists tend to define dispositions as concomitant with personality traits. ${ }^{2}$ A virtue ethics definition of dispositions, on the other hand, comes from the standpoint that dispositions can be learned, and are a combination of internal thought-processes and intentional actions. As Aristotle argues, virtues, and virtuous dispositions, not only involve right action, but also right thinking and right motivation. ${ }^{3}$ The virtue ethics standpoint regards dispositions as the combination of habits of mind with habits of action that occur with regular frequency over time and are intentional on the part of the individual.

This definition can be fleshed out by several scholars who have defined dispositions in their own work, all embedded within an Aristotelian notion of dispositions-as-virtues. For example, Hugh Sockett argues "dispositions are the property of the agent, manifest only in intentional action, and they function as predictions about human actions but are not the causes of them."4 Sockett suggests that dispositions have three characteristics. First, dispositions are defined by action, not just "being." Second, dispositions involve awareness of what one is doing. Third, dispositions involve acting with intentionality toward a specific end (not just being aware but intending to accomplish something or move toward a particular end with one's actions). He gives the example of the disposition toward friendliness. "So consider a friendly person, where friendliness is her disposition. She hugs and kisses other people whom she meets not just to be polite, or to offend them, but to be friendly. Her kisses are those of friendship, not malice, perversion, or accident. Her 
disposition to be friendly, we may say, is manifest in her actions." ${ }^{5}$ Sockett clarifies that dispositions are not causal - they do not cause something to happen. "However friendly our kisser may be, she will often have to judge whether it is appropriate to embrace this or that person. Dispositions to act always raise questions of judgment."” Sockett writes: "Our attribution of her friendliness and more important her self-awareness of her friendliness enable us to predict how she will behave. But 'being friendly' is not an explanation of her kissing people. The kissing is an instance or an example of her friendliness. To say she is friendly is informative but not explanatory." 7 To synthesize, according to Sockett, dispositions are defined as a complex interaction of judgement, reflection, and intention that are manifest in action, and this action happens in a continuous way over time such that people can predict someone's action-based on their known dispositions - without the disposition being the actual cause of the action. Furthermore, dispositions are acquired through a practice of exercising those dispositions toward flourishing. I want to particularly emphasize the idea of "a practice." The idea of "a practice" includes the notion that a person is intentionally doing something over and over again in a manner that they believe will lead to a more fruitful or flourishing version of both the practice itself and the person doing the practicing.

Other scholars can add to this definition. Laurance Splitter defines dispositions as a concept of intentional action that sits somewhere between "murky subjectivism" and "crude behaviorism." "Splitter further argues that dispositions are an interaction of thought (cognitive core) and action. It is not just a matter of behavior; the "behavior in which we are interested is the result of decisions and choices freely and intentionally made." ${ }^{.9}$ Furthermore, Splitter notes that there is a temporality to dispositions.

Dispositions are a set of actions (located in abilities) and inten- 
tions that recur over time and that tend to endure over time, even if not at all times, for all time. Splitter provides an example of this based on the question: Does he swim? If the answer to this question is, "Yes, he can swim," then the answer is getting at an action that is connected to a capability. However, if the answer is, "Yes, he is a swimmer," then the answer is getting at a disposition. The idea of "being" a swimmer gets at that combination of action embedded in ability (he has the ability to swim, and he does swim) plus the intentionality to swim (he swims on purpose) plus the temporal capacity (he swims on a regular enough basis that swimming has become a disposition; it is something we predict that he will do). Megan Watkins and Greg Noble add to this definition of disposition by arguing that dispositions are a "practiced capacity" and not just a "psychological attribute." ${ }^{10}$ Harvey Siegel further adds that dispositions are not behaviors. "Rather, they are tendencies to engage in particular sorts of behaviors."

From the standpoint of virtue ethics, dispositions are not merely traits or behaviors, but are attributes manifest by actions (but not solely behaviors or actions) that lead to a form of flourishing. This has ramifications for teaching and learning. If dispositions are merely personality traits, then it becomes difficult to conceive of how to teach and assess dispositions. On the other hand, if dispositions become defined as nothing more than a set of behaviors, this becomes easy to teach and assess, but misses out on key motivational and agential factors. It is only when we define dispositions from a virtue ethics standpoint that we can proceed next to a conversation about which dispositions can lead to scholarly flourishing, and then, how one might teach or facilitate the attainment of those dispositions.

\section{WHY IS A DISPOSITIONAL STANDPOINT IMPORTANT?}

Focusing on dispositions allows researchers, mentors, and 
those curious about the subject to grapple with a wider array of variables that affect human performance, practice, and motivation. The concept of dispositions gets at the inter-relationality between skills, knowledges, contexts, resources, motivations, time, and previous experience, and the ways that these variables can become habits of mind and habits of practice. A dispositional standpoint—or grappling with all these variables together-is particularly important when identity-making is at play.

Research by Joanne Profetto-McGrath provides an example of this. ${ }^{12}$ Her scholarship on education for nursing pointed to the fact that, for students to take on the identity of nurse (to see themselves as nurses, and not just as someone who had certain skills and knowledges), there needed to be an increase in dispositions associated with nursing, as measured by dispositional scales. In Profetto-McGrath's research, she focused particularly on the difference between critical thinking skills and critical thinking dispositions as a marker, not only of an increase in identifying as a nurse, but also in one's ability to use the skills and knowledges that were being taught in innovative and critical ways. ${ }^{13}$ Profetto-McGrath points out that dispositions are more than skills or knowledges; dispositions involve the ability to engage in and improve skills and knowledges over time, and apply them in novel ways and contexts. ${ }^{14}$ Skills might be requisite for a task, but dispositions are requisite for a practice. A skill is the ability to do something, whereas a disposition is the propensity to engage in that skill, reflect on that skill, and iterate on that skill over time. For a practice such as nursing, skills and dispositions are connected, but dispositions are more meaningful for understanding the fullness of practice and identity. While contrasting critical thinking skills and critical thinking dispositions, Profetto-McGrath writes, "Critical thinking dispositions are essential for the development of higher-order critical thinking and learning." ${ }^{15}$ She further argues, "Dispositions or habits of mind are crucial to critical thinking and many experts assert that with- 
out positive dispositions toward critical thinking, it does not happen or may be substandard." "Without a dispositional standpoint, or a focus on dispositions, nursing educators would be unable to plan curriculum, pedagogy, and associated learning experiences that foster the accrual of these dispositions that are so elemental to taking on the full identity of nurse and practicing nursing as more than just an assembly of skills and knowledges, but rather as a set of habits and ways of looking at the world that can be used in innovative ways and contexts.

Driscoll and Wells, in their work on the abilities of students to transfer what they learn about writing from coursework into other contexts or writing habits, find something similar: that a focus on dispositions makes all the difference. ${ }^{17}$ In their research, they found that, even though students could show that they had learned writing skills and knowledge about the mechanics of writing during a class devoted to the practice of writing, they did not necessarily transfer what they learned about writing to contexts outside of the class. However, when students had been shown to acquire dispositions associated with writing as a practice and as an identity, they were much more likely to be able to transfer knowledge and skills that they had learned around writing to different contexts, including writing outside of class. Dispositions were more important than knowledge and skills gains especially when the task involved transfer of knowledge and skills form one context to another or creating new skills or knowledges.

Lee and Herner-Patnode's research points to the need for a focus on dispositions particularly when identity-making or ontological shift is at play. ${ }^{18}$ Their work focuses on teacher candidates and the shift from pre-service teacher to in-service teacher. They foreground the identity shift that takes place as part of teacher education that allows the student to go from the standpoint of student to the standpoint of teacher. It is 
only when teacher educators focus on more than skills and knowledge, and spotlight the need to accrue specific dispositions, that students make the identity shift from student to teacher in a way that fleshes out their abilities and practices of teaching. The dispositional accrual is integral to the identity change from student to teacher.

By focusing on dispositions of doctoral students, particularly online doctoral students, we can grapple with the ways that skills, knowledges, motivations, contexts, resources, and experiences come together to inform the student experience and to facilitate the identity-based move from graduate student to independent scholar. Particularly in doctoral work, the aim is more than to teach skills and sets of knowledge. The aim is to create new ways of being and new identities for people who move from merely citing scholarship to developing and supporting their own ideas and finding their own voice. In my own experience, one of the most difficult shifts for a doctoral student to make is to go from someone who can cite research to someone who can speak back to the field and advocate for their own sense of knowing, ways of knowing, and research. That independent voice is part of an identity shift that moves beyond skills (knowing how to do something) and knowledges (knowing about something), to becoming knowers and do-ers. Focusing on dispositions allows us to grapple with those processes, and this allows us to think deeply about the experiences we provide for our doctoral students that would lead to positive disposition accrual.

\section{THE IMPORTANCE OF FACILITATING SCHOLARLY}

\section{DISPOSITIONS IN AN ONLINE DOCTORAL PROGRAM}

Scholarly dispositions can be accrued in multiple ways. Only some of these ways are open to online students. Online students have a uniquely difficult pathway when it comes to balancing the roles they have as student and in other areas of their lives. As Rockinson-Szap- 
kiw et al. show, attrition rates for residential (on-campus) doctoral programs range from $40 \%-70 \%$ (with colleges of Education toward the high end of that attrition continuum) within the United States, while online doctoral programs have attrition rates of close to $20 \%$ higher than that. ${ }^{19}$ A quantitative analysis of doctoral programs across the globe (including programs in US, UK, EU, Australia, China, and several other regions and countries) found that attrition rates for all doctoral programs are rising, and this is particularly true for online doctoral programs and students. ${ }^{20}$

Online students are different from their on-campus peers in many ways. Online students "maintain residence at a distance from campus (e.g., 100 miles to thousands of miles), choosing not to uproot their families for their educational goals. These candidates, especially those enrolled in EdD programs, remain in their careers as educators and administrators of academic institutions; thus, struggle to balance their home, school, and work lives." ${ }^{21}$ Often, online students, including online students in a doctoral program, are non-traditional students. ${ }^{22}$ That is to say, these students are often working adults who are trying to maintain family commitments and employment commitments in addition to doctoral work. Online students not only wrestle with the need to maintain a sense of "current life," but they also grapple with the increased effort it may take to create relationships with faculty and peers. Connection between faculty and students — and faculty presence — is a strong determiner of both persistence within a doctoral program and a student's sense of satisfaction with that program, and yet, in online programs, faculty connection and presence are difficult to create. ${ }^{23}$ Berry notes that "both online students and faculty said that it was more difficult to connect online than in a traditional class and that online connection required more effort inside and outside of the classroom." 24 
The distance, the separation, the pull of outside-of-school life makes it difficult for online doctoral students to have the "access" (as Prawat notes) to institutional support structures that facilitate reflection and strategies for accruing scholarly dispositions. It is difficult for online doctoral students to engage in communities of scholarly virtues, as advocated by Thein and Beach and Ferkany and Creed. ${ }^{25}$ This is evident as I compare my own doctoral experience with the experiences of the online doctoral students at my current institution.

As I have written before, many of the scholarly dispositions and habits that I learned as a $\mathrm{PhD}$ student took place in more tacit ways. ${ }^{26}$ Professors rarely stated in a syllabus that students should write their final papers with an eye toward sending those papers to conferences or academic journals. However, in quick conversations to and from class, professors would ask if I had thought about sending my final paper to a particular journal or conference. Peers would ask, as we sat together in the TA (teaching assistant) or RA (research assistant) offices, about whether or not I was going to a particular conference, and whether or not I had published something recently. My peers and I would continue conversations about what we had learned during class as we walked from one building on campus to another, and thus model for each other the importance of curiosity and scholarly engagement that was more a form of life than a practice reserved for the classroom alone. We had get-togethers at faculty homes where scholarly debate, doubt, and open-mindedness were modeled. So much of the explicit training I received on how to be a scholar (through lunchtime workshops on professional dress standards, information on what to expect at academic conferences, and firsthand information on how academic journals operate) did not happen in a specific course, but happened in optional on-campus gatherings. I became part of a community that practiced the dispositions (virtues) of scholarly activity because I was part of a campus community. If I 
had only had access to what was said during class time in a classroom, I would have missed out on some of the key strategies and "normalizing influences" that guided my own academic progression and attainment of scholarly dispositions.

Meeting the needs of our online students and facilitating the development of scholarly dispositions within our online students might mean dedicating time within each course for dedicated practice of those dispositions, and reflection on those dispositions. It will mean grappling with ways to offer online students the experiences (often foundational dispositional experiences) that will facilitate the accrual of scholarly dispositions for our online students. In order to address these needs, I have worked with an amazing group of colleagues who have piloted the strategies discussed below. These strategies represent a first effort to facilitate the accrual of scholarly dispositions as an online student.

As mentioned above, scholarly dispositions involve accruing habits of practice and habits of thinking. Yet, one of the challenges with being on online student is that you don't often get to see habits of practice and habits of thinking outside of the classroom. Several colleagues and I have begun to address these issues. ${ }^{27}$ One of the ways we have addressed this issue it to be more explicit during class time about the habits we engage in as professors. For example, some of us now start our classes by talking about the writing we have done or the research practices we have engaged in during the past week. We are explicit about the time it took, how we made time to do the research or writing, as well as about our own habits of doing these things. For some of us, this means creating a few hours every day to work on research and writing. Others of us need more concentrated time, so we talk about setting aside a writing or research day each week. The goal for this brief discussion at the beginning of class is not to preach about best practices; rather, it is to publicly reflect on 
our own habits of mind and practice that have become dispositional in nature. It is to model dispositions toward scholarship. We then encourage students to talk about the research or writing they have done during that week. We create a time and space to spotlight scholarly dispositions and encourage students, through describing what these dispositions look like in our own lives, to practice these dispositions themselves. The time before class lasts 20-30 minutes of a three-hour class period. At first, many of us wondered if spending this amount of time on a topic that was not part of the "content area" of the course would be meaningful. The feedback we have received is that this activity has been significant for students as they consider what it looks like to live the life of a scholar. This time spent in class, before the "real" work of the class begins, allows us to model dispositions of curiosity, and dispositions toward engaging in scholarship.

Another strategy we have deployed is to be far more conscious about including our online students in scholarly conversations where we model scholarly dispositions of critical thinking and open-mindedness. This has meant setting up online book groups, online discussion sessions, online panels that specifically address scholarly dispositions, and even online social hours. The intention has been to find ways to take the outside-of-class experiences that were meaningful for us as graduate students and create ways to have those experiences online. When we first started down this pathway, we worried about the attendance at such sessions. Would students show up? Would faculty? Thus far, the feedback and the experiences have been positive. Many faculty have found that joining these discussions and social events online has actually been easier than setting up similar experiences on campus. It turns out that the time it takes to rent a room on campus, decide whether food can be served, worry about parking, and all the other worries that go into planning events in a bricks-and-mortar space was time that was well spent in other 
activities. It takes just as much planning to get people to put an event on their calendar that happens online as one that happens on campus or at the bar near campus. As we have discussed the outcomes thus far as a faculty, we have reflected on the fact that these planned events will likely never supplant the spur-of-the-moment hallway discussions, or lunches, or various other meetings that arise simply because two or more people are interested in continuing a discussion outside of class. However, knowing this, we have been far more intentional about making sure that there are online events that are planned. Even if our students miss out on the spur-of-the-moment opportunities for discussion and modeling of scholarly dispositions, they do have access to spaces where these dispositions are modeled outside of class time. These outside activities are where we can model and encourage scholarly dispositions of doubt and listening and open-mindedness.

Another strategy we have deployed is being more intentional about highlighting the conferences we go to and the ways we hear about or know about conferences that are relevant to our areas of work. We talk about the processes we deploy when we are selecting a journal for our work. We talk about the process of taking a conference presentation and honing it to become a journal article submission. While all these activities listed above sound like, well, activities, we focus on the ways that we create a cadence for engaging in these activities. We focus on the ways that these activities, engaged in over time and at regular intervals, have resulted in dispositions toward scholarship. We have taken on the identity of scholars through engaging in these activities over time, with intention, such that these activities become a reflection of who we are and how we live, not just what we do. To connect to an example above, we have become scholars (or swimmers) not just people who are capable of scholarship (or people who are capable of swimming). We talk about how that happens and encourage our students to do the same. 
Finally, we have developed a course that specifically focuses on the accrual of scholarly dispositions. We have developed explicit curriculum meant to reveal the hidden curriculum of graduate school. The coursework involves the study of scholarly dispositions (what are they?; can you acquire them?; if so, how?). The coursework further involves reflection on the barriers to accruing these dispositions that may be encountered by online students. We think, together, about pathways for the development of these important dispositions.

\section{CONCLUSION}

Many universities are moving toward online doctoral programs. The National Center for Education Statistics (NCES), within the US, reports that the largest growth in doctoral degrees is due to online doctoral courses and programs. ${ }^{28}$ In fact, NCES reports that the largest driver in increases of all post-baccalaureate degrees is due to the rise of online degree programs. ${ }^{29}$ Multiple state governments (for example, Oregon) are predicting that COVID-19 has only spurred the move toward online postbaccalaureate programs as workers consider ways to upskill for the changing economy. ${ }^{30}$ This increasing move toward online graduate programs and coursework precipitates the need for further conversations around and strategies toward supporting online students. This conversation is particularly needed for online doctoral students whose programs aim toward an "apprenticeship model" where students take on the life, skills, and dispositions of their mentors to fully engage in the work of the profession. I am convinced that we need greater purpose with and attention to facilitating scholarly dispositions for online students. The only way to achieve that is to be much more intentional about scaffolding practice, community, strategy, and reflection on scholarly dispositions into our courses. 
1 Please see information on the Carnegie Classification System located here: https://carnegieclassifications.iu.edu/classification descriptions/basic.php. 2 Auke Tellegen, "Personality Traits: Issues of Definition, Evidence, and Assessment," in Thinking Clearly About Psychology: Essays in Honor of Paul E. Meebl, Vol. 1: Matters of Public Interest, Vol. 2: Personality and Psychopathology, eds. Dante Cicchetti and W.M. Grove (Minneapolis: University of Minnesota Press, 1991); Brent W. Roberts and Richard W. Robins, "Broad Dispositions, Broad Aspirations: The Intersection of Personality Traits and Major Life Goals," Personality and Social Psychology Bulletin 26, no. 10 (2000): 1284-1296. See also: William Damon, "Dispositions and Teacher Assessment: The Need for a More Rigorous Definition," Journal of Teacher Education 58, no. 5 (2007): 365-369.

3 Aristotle, Nicomachean Ethics, Books II-IV, trans. C.C.W. Taylor (Oxford: Oxford University Press, 2006).

4 Hugh Sockett, "Dispositions as Virtues: The Complexity of the Construct," Journal of Teacher Education 60, no. 3 (2009), 292.

5 Sockett, "Dispositions as Virtues,” 294.

6 Sockett, “Dispositions as Virtues,” 294.

7 Sockett, "Dispositions as Virtues," 295.

8 Laurance J. Splitter, "Dispositions in Education: Nonentities Worth Talking About," Educational Theory 60, no. 2 (2010), 209.

9 Splitter, "Dispositions in Education," 210.

10 Megan Watkins and Greg Noble, Cultural Practices and Learning: Diversity, Discipline and Dispositions in Schooling (Sydney: University of Western Sydney Press, 2008).

11 Harvey Siegel, "What (Good) are Thinking Dispositions?" Educational Theory 49, 
no. 2 (1999): 207-221.

12 Joanne Profetto-McGrath, "The Relationship of Critical Thinking Skills and Critical Thinking Dispositions of Baccalaureate Nursing Students," Journal of Advanced Nursing 43, no. 6 (2003): 569-577.

13 Profetto-McGrath, "The Relationship of Critical Thinking."

14 Profetto-McGrath, "The Relationship of Critical Thinking."

15 Profetto-McGrath, “The Relationship of Critical Thinking,” 574.

16 Profetto-McGrath, “The Relationship of Critical Thinking,” 575.

17 Dana Lynn Driscoll, and Jennifer Wells, "Beyond Knowledge and Skills: Writing Transfer and the Role of Student Dispositions," Composition Forum 26, no. 1 (2012).

18 Young Ah Lee and Leah Hemer-Patnode, "Developing Teacher Candidates’ Knowledge, Skills, and Dispositions to Teach Diverse Students,” Journal of Instructional Psychology 37, no. 3 (2010): 222-235.

19 Amanda J. Rockinson-Szapkiw, Lucinda S. Spaulding, and Maria T. Spaulding, "Identifying Significant Integration and Institutional Factors that Predict Online Doctoral Persistence," The Internet and Higher Education 31, no. 1 (2016): 101-112. 20 Cathrine Ames, Ronald Berman, and Alex Casteel, "A Preliminary Examination of Doctoral Student Retention Factors in Private Online Workspaces," International Journal of Doctoral Studies 13, no. 1 (2018): 79-107.

21 Ames, Berman, and Casteel, “A Preliminary Examination,” 102.

22 Ames, Berman, and Casteel, "A Preliminary Examination."

23 Ames, Berman, and Casteel, "A Preliminary Examination,” 103.

24 Sharla Berry, "Student Support Networks in Online Doctoral Programs: Exploring Nested Communities," International Journal of Doctoral Studies 12, no. 1 (2017), 36. 25 Matt Ferkany and Benjamin Creed, "Intellectualist Aristotelian Character 
Education: An Outline and Assessment," Educational Theory 64, no. 6 (2014): 567-587; Amanda Haertling Thein and Richard Beach, "Mentoring Doctoral Students Towards Publication Within Scholarly Communities of Practice," in Publishing Pedagogies for the Doctorate and Beyond, eds. Claire Aitchison, Barbara Kamler, and Alison Lee (London: Routledge, 2010).

26 Lee S. Duemer and Heather Greenhalgh-Spencer, "Developing Dispositions of Collegiality and Professionalism in Online Doctoral Programs," in Handbook of Research on Developing Students' Scholarly Dispositions in Higher Education, ed. Aaron Samuel Zimmerman (Hershey: IGI Global, 2021).

27 Deumer and Greenhalgh-Spencer, "Developing Dispositions of Collegiality."

28 National Center for Education Statistics, "Fast Facts: Distance Learning," https:// nces.ed.gov/fastfacts/display.asp?id=80.

29 National Center for Education Statistics, "Post-Baccalaureate Enrollment," https:// nces.ed.gov/programs/coe/indicator chb.asp.

30 State of Oregon Employment Department, "Growth in Distance Learning Outpaces Total Enrollment Growth,” August 11, 2020, https://www.qualityinfo.org/-/ growth-in-distance-learning-outpaces-total-enrollment-growth. 